\title{
EVOLUÇÃO GEOQUÍMICA E MINERALÓGICA EM PERFIS DE ALTERAÇÃO SOBRE ROCHAS SERPENTINIZADAS NO SUDOESTE DE MINAS GERAIS ${ }^{(1)}$
}

\author{
Pablo Vidal-Torrado( ${ }^{(2)}$, Rosa Calvo ${ }^{(3)}$, Felipe Macias $^{(3)}$, Sebastião G. \\ Carvalho $^{(4)} \&$ Alexandre Christofaro Silva ${ }^{(5)}$
}

\begin{abstract}
RESUMO
Estudou-se a evolução geoquímica e mineralógica em três perfis distintos de alteração de rochas serpentinizadas que ocorrem nas imediações dos municípios de Alpinópolis e Fortaleza de Minas, no sudoeste do Estado de Minas Gerais, sob regimes de umidade e de temperatura údico e térmico, respectivamente. Nas condições atuais, o grau de evolução química e mineralógica é moderado em relação ao desenvolvido sobre outros tipos de rochas básicas e ultrabásicas da mesma área, caracterizando-se por uma importante perda de $\mathrm{Na}$ e $\mathrm{Mg}$ e, em menor proporção, de Ca e Si. O Al (localmente também o Fe) é o elemento menos móvel dos sistemas. O K é escasso no material de origem e nas zonas de alteração, e ocorre enriquecimento desse elemento nos horizontes superficiais por aporte externo. Os minerais primários mais facilmente intemperizáveis, como o talco, a tremolita e a clorita trioctaédrica, são abundantes ainda na fração argila desses solos tropicais com composição mineralógica pouco comum, mas são todos termodinamicamente instáveis. Do ponto de vista geoquímico, o processo de alteração atual pode ser definido como uma bissialitização, que pode coincidir com ferruginização, com formação de minerais trioctaédricos secundários por transformação direta de estrutura e também por neoformação, todos coexistindo com os minerais primários residuais. No entanto, as fases de maior evolução, em volumes com drenagem mais eficiente, tendem à monossialitização, com formação de caulinitas de diferentes graus de cristalinidade. A assembléia mineralógica
\end{abstract}

(1) Parte da tese de livre docência do primeiro autor. Trabalho financiado pela FAPESP e pela Universidade de Santiago de Compostela. Recebido para publicação em dezembro de 2005 e aprovado em maio de 2007.

(2) Professor do Departamento de Ciência do Solo, Escola Superior de Agricultura Luiz de Queiroz - ESALQ/USP. Caixa Postal 09, CEP 13418-900 Piracicaba (SP). Bolsista do CNPq. E-mail: pablo@esalq.usp.br

(3) Professor do Departamento de Edafoloxia, Facultad de Bioloxia, Universidad de Santiago de Compostela. CP 15706, Santiago de Compostela, Espanha. E-mail: edfmac@usc.es

(4) Professor do Instituto de Geociências e Ciências Exatas, Universidade Estadual Paulista - UNESP. Rio Claro, CEP 13500-230 Rio Claro (SP). E-mail: carvalho@rc.unesp.br

${ }^{(5)}$ Professor da Universidade Federal dos Vales do Jequitinhonha e Mucuri - UFVJM. Caixa Postal 38, CEP 39100-000 Diamantina (MG). E-mail: christo@jknet.com.br 


\author{
existente evidencia a metaestabilidade e caráter incipiente do sistema \\ pedogenético.
}

Termos de indexação: solos tropicais, solos pouco desenvolvidos, rochas ultramáficas, serpentinitos, talco, clorita, interestratificados.

\title{
SUMMARY: GEOCHEMICAL AND MINERALOGICAL EVOLUTION IN ALTERATION PROFILES ON SERPENTINIZED ROCKS IN SOUTHWESTERN MINAS GERAIS, BRAZIL
}

\begin{abstract}
The geochemical and mineralogical evolution was studied in three different alteration profiles of ultramafic (serpentine) rocks near Alpinópolis and Fortaleza de Minas, in southwestern Minas Gerais State (Brazil). Soil moisture and temperature regimes are udic and thermic, respectively. The current chemical and mineralogical evolution degree is moderate compared to other basic and ultramafic material of the same area and is characterized by significant losses of $\mathrm{Na}$ and $\mathrm{Mg}$ and, to a lesser extent, of Ca and Si. Very little $K$ was found in the parent material and in the alteration zones, whereas the surface horizons are enriched by external addition. Aluminum (locally also $\mathrm{Fe}$ ) are the least mobile elements of the system. The primary easily weatherable minerals, such as talc, tremolite and also trioctahedral chlorite, are abundant in the clay fraction and are all thermodynamically unstable in these tropical soils of rare mineralogical composition. The ongoing geochemical process can be defined as bisialitization that can coincide with ferruginization, with the formation of trioctahedric secondary minerals by direct transformation of the structure and also by neoformation, all coexisting with the residual primary minerals. However the most weathered phases observed in well-drained positions, tended to monosialitization with kaolinite formation of variable crystallinity degree. The mineralogical assembly evidences the metastability and incipient nature of the pedogenetic system.
\end{abstract}

Index terms: tropical soils, little weathered soils, ultramafic rocks, serpentine, talc, chlorite, interstratified minerals.

\section{INTRODUÇÃO}

A serpentinização é um processo de alteração hidrotermal metassomático que afeta as rochas ultrabásicas e básicas quando submetidas ao metamorfismo regional na fácies xisto verde. Nessas condições, sob temperaturas entre 200 e $500{ }^{\circ} \mathrm{C}$, os minerais primários, em particular as olivinas, são transformados, por ação de fluidos ricos em $\mathrm{Mg}$ e metais pesados, em minerais mais estáveis para as condições de superfície. A serpentinização dessas rochas pode ser total ou parcial. Quando parcial, coexiste com minerais do grupo das serpentinas (principalmente antigorita e crisotilo), uma associação mineral caracterizada por brucita, talco, anfibólios fibrosos, cloritas, calcita, dolomita, espinélios (magnetita e cromita, entre outros), saponitas, etc. Todos esses minerais poderão ocorrer em quantidades variáveis, dependendo sempre da rocha preexistente (protólito) e das características do fluxo serpentinizante (Malpas, 1991; Coleman \& Jove, 1992). Portanto, as rochas serpentinizadas possuem elevadas concentrações de $\mathrm{Mg}$ e evolução frente ao intemperismo muito heterogênea, uma vez que se compõem de minerais de contrastada resistência à alteração.
O intemperismo de rochas serpentinizadas é muito afetado pelas condições climáticas, pela composição original do protólito, pelo grau de serpentinização final e pela composição das águas superficiais (Coleman \& Jove, 1992). Entretanto, em linhas gerais, os processos de alteração e pedogênese apresentam características muito peculiares, como uma pequena espessura do manto de alteração e dos solos, em comparação com os de outros materiais nas mesmas condições climáticas e que ocupam superfícies geomórficas semelhantes (Jenny, 1980), pedregosidade e rochosidade considerável, baixa fertilidade natural e, freqüentemente, problemas de toxicidade ligados à existência de elevadas concentrações de metais pesados, como $\mathrm{Cr}, \mathrm{Ni}$, Co e $\mathrm{Cu}$, principalmente (Roberts \& Proctor, 1991). Associada a esses aspectos, é freqüente a presença de vegetação escassa e com endemismos e, ou, nanismos, o que, juntamente com os aspectos anteriormente citados, configura um ambiente edáfico característico, que se convencionou denominar síndrome serpentínica. Essa síndrome tem atraído a atenção mundial de fitoecólogos e pedólogos desde o século passado, mas são recentes os estudos de relações solo-planta nesses ecossistemas (Roberts \& Proctor, 1991). 
Diversos trabalhos têm se ocupado dos processos de alteração e pedogênese sobre esses materiais em diferentes condições climáticas, desde tropicais (Trescases, 1975; Ségalen et al., 1980; Schwertman \& Latham, 1986) a frias (Bulmer et al., 1992; Adamson et al., 1993) e, principalmente, temperadas (Rabenhorst et al., 1982; Cleaves, 1983; Calvo de Anta et al., 1987; Bonifácio et al., 1997; Aguilar et al., 1998; Lee et al., 2003).

A maioria dos trabalhos sobre rochas ultramáficas no Brasil é dedicada à sua geologia ou aos estudos geoquímicos da alteração, ambos visando ao interesse econômico, sobre as mineralizações ricas em metais, como Ni e Cr. Do ponto de vista geomorfológico, boa parte desses maciços ultramáficos, que também são portadores de jazidas lateríticas de $\mathrm{Ni}$, aparecem, de modo geral, sob a forma de relevos tabulares, em que os pontos altos se constituem em remanescentes de antigas superfícies de aplainamento (Sul Americana ou Velhas, descritas por Lester King) de idade terciária (Melfi et al., 1980). Estudos da geoquímica de alteração supérgena voltados para a gênese desses depósitos residuais de $\mathrm{Ni}$ foram feitos por diversos autores (Melfi et al., 1980; Oliveira \& Trescases, 1980; Esson, 1983), ressaltando a natureza caulinítica ou oxídica dos Latossolos que recobrem essas lateritas. Oliveira \& Trescases (1980) descreveram a existência de profundos perfis de alteração no planalto central brasileiro, e a serpentina está presente apenas na fácies saprolito grosseiro, desaparecendo nas fácies lateríticas sobrejacentes. Os mesmos autores (Trescases \& Oliveira, 1980) estudaram o Morro do $\mathrm{Ni}$, localidade próxima à área de estudo deste trabalho, onde também descrevem o perfil de alteração laterítico de um morrote tabular de $1.000 \mathrm{~m}$ de altitude (provavelmente remanescente ou vestígio das superfícies Sul Americana ou Velhas), situado sobre os serpentinitos da Série Minas.

No ambiente subtropical do Rio Grande do Sul, em superfícies rejuvenescidas, os solos são similares aos encontrados no ambiente temperado, com pequena espessura e presença abundante de minerais intemperizáveis (Meneggoto,1983), sendo considerados por Pinto \& Kampf (1996) como os solos menos intemperizados do Rio Grande do Sul.

Em trabalhos de campo realizados para estudos da natureza geológica no greenstone belt Morro do Ferro (Carvalho et al., 1993), no sudoeste de Minas Gerais, região de clima tropical úmido com estação seca definida, muitas das ocorrências de serpentinitos foram facilmente mapeadas devido ao controle estrutural do relevo exercido por essas rochas, com afloramentos rochosos e presença de solos pouco profundos, situação semelhante à descrita para os ambientes subtropical e temperado (Alexander et al., 1985).

Segundo Carvalho et al. (1993), os serpentinitos do sudoeste de Minas Gerais derivam-se de peridotitos komatiiticos. As serpentinas derivam-se diretamente de olivinas e indiretamente de talco, tremolita, actinolita e clorita, quando esses minerais representam fases intermediárias de alteração das olivinas.

O objetivo deste trabalho foi apresentar e discutir as tendências de evolução mineralógica e geoquímica dos três perfis de solos derivados de rochas serpentinizadas, com regime térmico e údico, situados em superficies geomórficas rejuvenescidas do sudoeste de Minas Gerais.

\section{MATERIAL E MÉTODOS}

\section{Caracterização dos locais dos estudos}

Os estudos foram realizados em três perfis de alteração desenvolvidos de rochas serpentinizadas, em diferentes locais do greenstone belt Morro do Ferro, nas proximidades dos municípios de Fortaleza de Minas - perfil 1 (P1) e Alpinópolis - perfil 2 (P2) e perfil 3 (P3) (Figura 1). Os solos desses perfis foram descritos, analisados e classificados por Vidal-Torrado et al. (2006), segundo o Sistema Brasileiro de Classificação de Solos (Embrapa, 1999), como Chernossolo Háplico Férrico típico (P1), Neossolo Regolítico eutrófico típico (P2) e Cambissolo Háplico Eutroférrico léptico (P3).

A associação rochosa de natureza vulcanosedimentar que compõe o greenstone supramencionado encontra-se embutida tectonicamente por falhas ou por outras estruturas sinformais em um embasamento granítico-migmatítico-gnáissico arqueano, regionalmente denominado Complexo Campos Gerais (Carvalho et al., 1993). Localmente, as unidades litológicas estudadas, além de serpentinitos, contêm também outros litotipos, como talco xisto, tremolita xisto, clorita xisto e cherts de natureza diversa, podendo ocorrer ainda intercalações com granito/ gnaisses e anfibolitos. O P1, próximo à cidade de Fortaleza de Minas, está localizado no topo convexo de uma colina sobre rochas serpentinizadas circundadas por talco-xistos que apresentam relevo ondulado (Figura 1). Os perfis P2 e P3, localizados nas proximidades da cidade de Alpinópolis, ocorrem em área de relevo suave e com variadas litologias no seu entorno, dentre as quais se destacam anfibolitos, xistos e granitos/gnaisses de composição variada (Figura 1); na base do P2 foi constatado o contato abrupto entre o serpentinito e o saprolito granítico. Nos três perfis, a rochosidade é muito abundante e balizada por afloramentos de rochas serpentinizadas, o que permitiu a delimitação das áreas de estudo.

De forma geral, os serpentinitos de ambas as áreas apresentam a seguinte composição mineralógica: serpentina (30-90\%), actinolita/tremolita (0-40 \%), clorita (0-18\%), opacos (5-15\%), carbonatos (0-12\%), olivina (0-5 \%), talco (0-1\%) e clinopiroxênio (0-1\%) (Carvalho et al., 1993). 


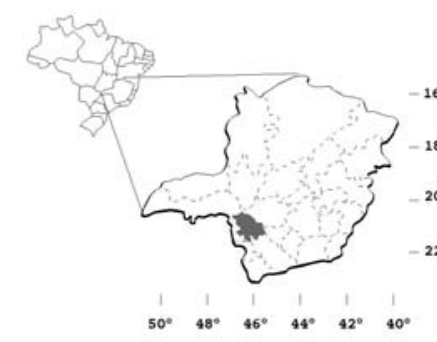

Fortaleza de Minas
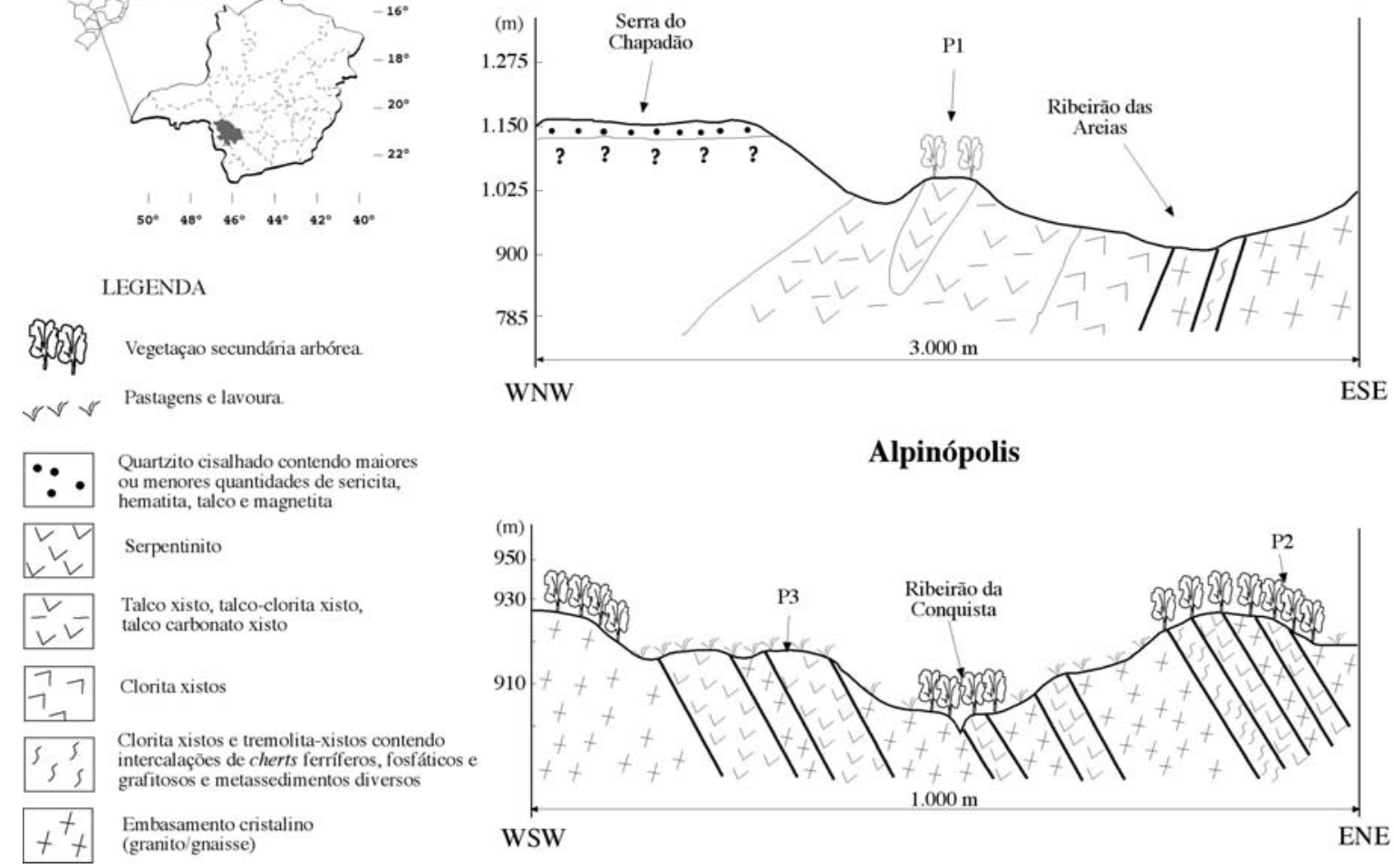

Alpinópolis

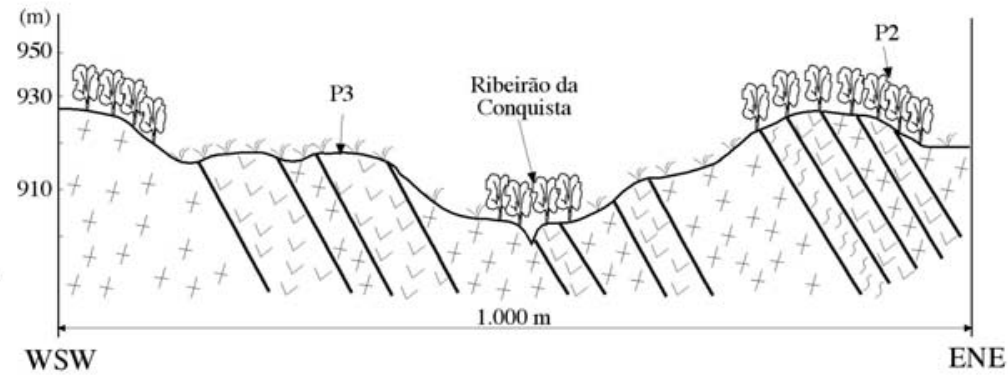

Figura 1. Localização da área de estudo e representação esquemática do relevo, litologia e situação dos perfis estudados.

O clima atual se caracteriza por coincidirem as maiores temperaturas com o período mais chuvoso e as menores com o período seco. As médias anuais de precipitação e temperatura são de $1.500 \mathrm{~mm}$ e $20^{\circ} \mathrm{C}$, respectivamente. As chuvas são mais abundantes no período de outubro a abril, com precipitações médias mensais entre 150 e $250 \mathrm{~mm}$, e o período mais seco é de junho a agosto, com precipitações médias mensais entre 25 e $30 \mathrm{~mm}$. A temperatura média dos meses mais frios (junho-julho) é de $15^{\circ} \mathrm{C}$, e a dos meses mais quentes (dezembro a março), de 22 a $23^{\circ} \mathrm{C}$. Essas características climáticas correspondem aos regimes de temperatura e umidade térmico e údico, respectivamente (Soil Survey Staff, 1996). Embora secundária, a vegetação nativa está presente e se trata de floresta estacional semidecidual com espécies de cerrado.

\section{Análises físicas, químicas e mineralógicas}

Foram coletadas amostras de rochas (com diferentes graus de alteração) e dos horizontes do solo nos três perfis estudados. A análise total de rochas, feita em amostras moídas após trituração em moinho mecânico de ágata, da terra fina e das argilas (fração $<0,002 \mathrm{~mm}$ ) dos horizontes foi realizada por fusão alcalina, segundo o método descrito por ASTM (1991) e Bertsch \& Bloom (1996), utilizando metaborato de lítio como fundente em um fluxer automático LECO
FX6-200, com posterior dissolução em meio ácido e determinação por espectrofotometria de absorção atômica de chama do conteúdo de Al, Fe, Mn, Ca, Mg e $\mathrm{Si}$; o $\mathrm{Na}$ e o $\mathrm{K}$ foram determinados por espectrofotometria de emissão de chama. Na fração $<2$ mm determinou-se também: $\mathrm{pH} \mathrm{H}_{2} \mathrm{O}(1: 2,5) ; \mathrm{pH}$ de abrasão (Grant, 1969); análise granulométrica (Camargo et al., 1986 ); C orgânico e bases trocáveis (Raij et al., 1987); e extrações seletivas de Fe, Al e Mn, utilizando o método do ditionito-citrato adaptado por Buurman et al. (1996) e o do $\mathrm{NH}_{4}$-oxalato (Blakemore et al., 1987). A preparação das amostras para análises da mineralogia da fração argila realizouse seguindo os métodos descritos por Camargo et al. (1986), sendo as amostras analisadas por difratometria de raios $\mathrm{X}$ sob radiação de $\mathrm{Cu}$ e filtro de $\mathrm{Fe}$, obtendose difratogramas de agregados orientados.

Preparou-se uma solução de equilíbrio solo-água (relação 1:2), onde, após uma semana de tempo de contato, determinou-se, após filtragem prévia por 0,45 $\mu \mathrm{m}: \mathrm{pH}$, condutividade elétrica, $\mathrm{NO}_{2}^{-}, \mathrm{NO}_{3}^{-}$, $\mathrm{SO}_{4}{ }^{=}, \mathrm{Cl}^{-}, \mathrm{F}^{-}, \mathrm{HCO}_{3}{ }^{-}, \mathrm{Ca}^{2+}, \mathrm{Mg}^{2+}, \mathrm{Na}^{+}, \mathrm{K}^{+}$e $\mathrm{NH}_{4}^{+}$, por cromatografia iônica (DIONEX 4500), sendo Si, Fe e Al determinados por absorção atômica. As atividades iônicas e os índices de saturação mineral foram calculados segundo Kharaka et al. (1989), utilizando-se o programa Solmineq 88. 


\section{RESULTADOS E DISCUSSÃO}

\section{Tendências da evolução geoquímica}

As áreas serpentinizadas estudadas caracterizamse por apresentarem solos pouco desenvolvidos, quando comparados principalmente com os Nitossolos e Latossolos formados nas proximidades (Vidal-Torrado, 1999b), porém sobre outros tipos de rochas básicas e ultrabásicas. Adicionalmente, apresentam feições de intensa dinâmica erosivo-acumulativa, com contatos líticos e lítico-fragmentários próximos à superfície, elevada rochosidade superficial e interna e fraca diferenciação de horizontes. Rochas com variados graus de alteração aparecem incluídas em uma matriz de maior evolução, com estrutura similar à dos horizontes $\mathrm{C}$ ou $\mathrm{B}$. O horizonte superficial apresenta elevada saturação do complexo de troca por $\mathrm{Mg}$ e Ca, oscilando a relação Ca/Mg entre 0,6 e 3,4 (Quadro 1). Muito freqüentemente, os processos erosivos favorecem a presença de horizontes A moderados, menos espessos, mas com atributos físico-químicos similares aos anteriores. Os solos exibem texturas que variam de franco, franco-argiloso a argila, com elevados conteúdos de silte e argila, entre 210 e $400 \mathrm{~g} \mathrm{~kg}^{-1} \mathrm{e}$ 230 e $580 \mathrm{~g} \mathrm{~kg}^{-1}$, respectivamente (Quadro 1). O pH em água é neutro a ligeiramente básico $(6,4$ a 7,0$)$, com pouca oscilação entre horizontes.

A análise total da rocha menos alterada (Rf de P1) é característica dos materiais ultrabásicos submetidos à serpentinização, com elevada proporção de $\mathrm{MgO}$
(230 $\left.\mathrm{g} \mathrm{kg}^{-1}\right)$, baixa relação $\mathrm{Ca} / \mathrm{Mg}(0,19)$, moderada participação de $\mathrm{SiO}_{2}\left(471 \mathrm{~g} \mathrm{~kg}^{-1}\right)$ e escasso conteúdo de $\mathrm{Al}$ e, sobretudo, de elementos alcalinos, não alcançando $15 \mathrm{~g} \mathrm{~kg}^{-1}$ a soma de $\mathrm{K}_{2} \mathrm{O}+\mathrm{Na}_{2} \mathrm{O}$ (Quadro 2). As análises realizadas por Carvalho et al. (1993), em amostras de rochas serpentinizadas da área de Alpinópolis, coletadas em sondagens a profundidades superiores a $30 \mathrm{~m}$, indicam que a rocha fresca dessa área pode superar $350 \mathrm{~g} \mathrm{~kg}^{-1}$ de $\mathrm{MgO}$, com relações $\mathrm{Ca} / \mathrm{Mg}$ entre 0,02 e 0,08 (Quadro 2) e conteúdos de $\mathrm{SiO}_{2}$ ao redor de $400 \mathrm{~g} \mathrm{~kg}^{-1}$.

A evolução geoquímica constatada durante a alteração e pedogênese evidencia o caráter aberto dos sistemas estudados, com importante perda dos elementos mais móveis, alcalinos e alcalino-terrosos, e clara tendência dos materiais em direção ao sistema residual (Chesworth, 1973) (Figura 2). A evolução do $\mathrm{pH}$ de abrasão permite seguir mais nitidamente os processos de intemperismo (Figura 3). Assim, em rochas não ou pouco alteradas o $\mathrm{pH}$ de abrasão oscila entre 9,1 e 10,0, decrescendo para 7,5-8,0 em rochas alteradas, até $6,5-5,8$ nos horizontes $\mathrm{C}$ e $\mathrm{B}$. Nos horizontes superficiais não submetidos a rejuvenescimento, o pH de abrasão decresce até valores entre 6,0 e 5,3 .

O grau de evolução geoquímica alcançado nos horizontes mais desenvolvidos não é muito intenso, mantendo-se longe do campo habitual dos horizontes ferralíticos de climas quentes e úmidos, resultado que corrobora o de outros estudos, que evidenciam evolução geoquímica pouco expressiva para as rochas

Quadro 1. Atributos físicos e químicos dos solos estudados

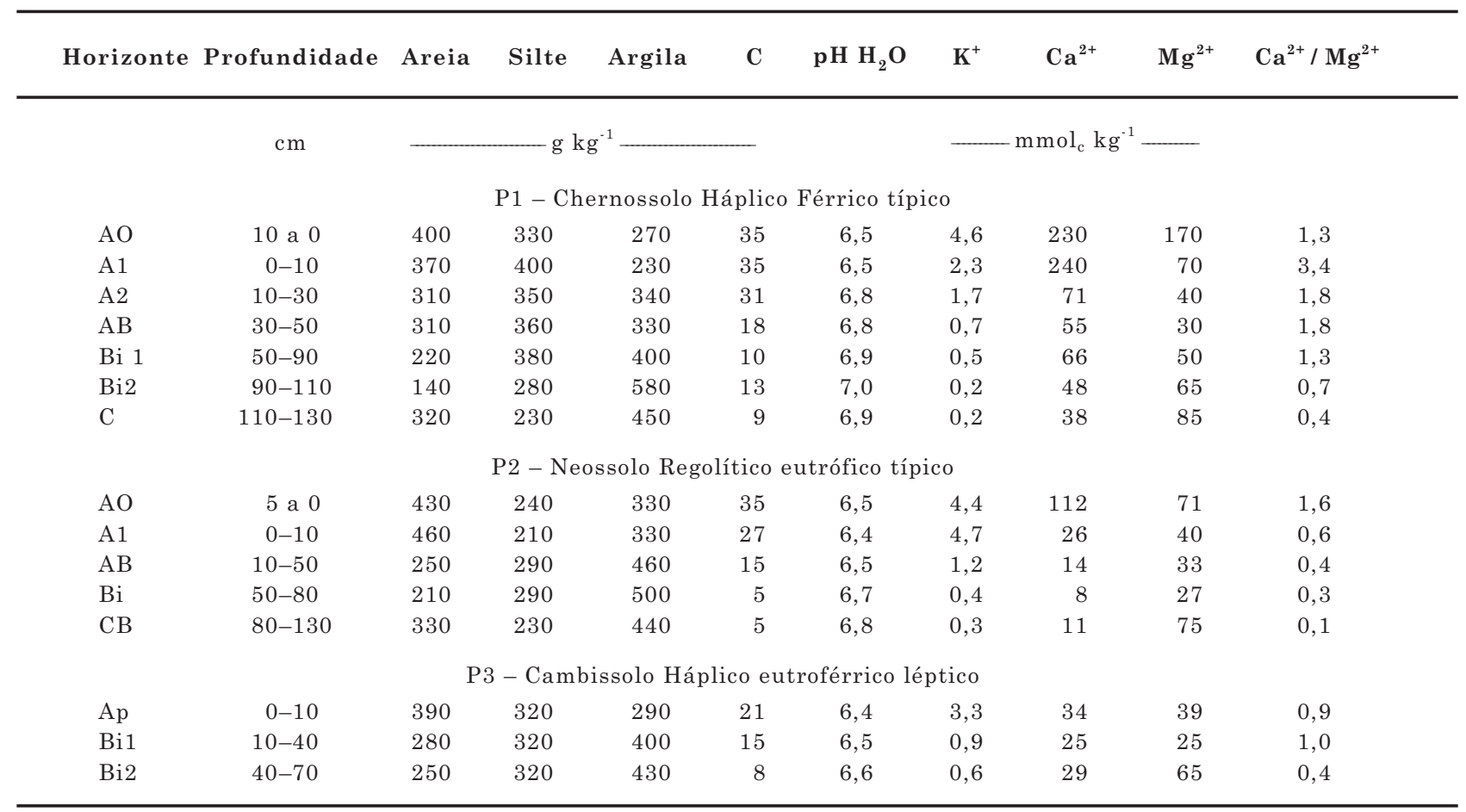




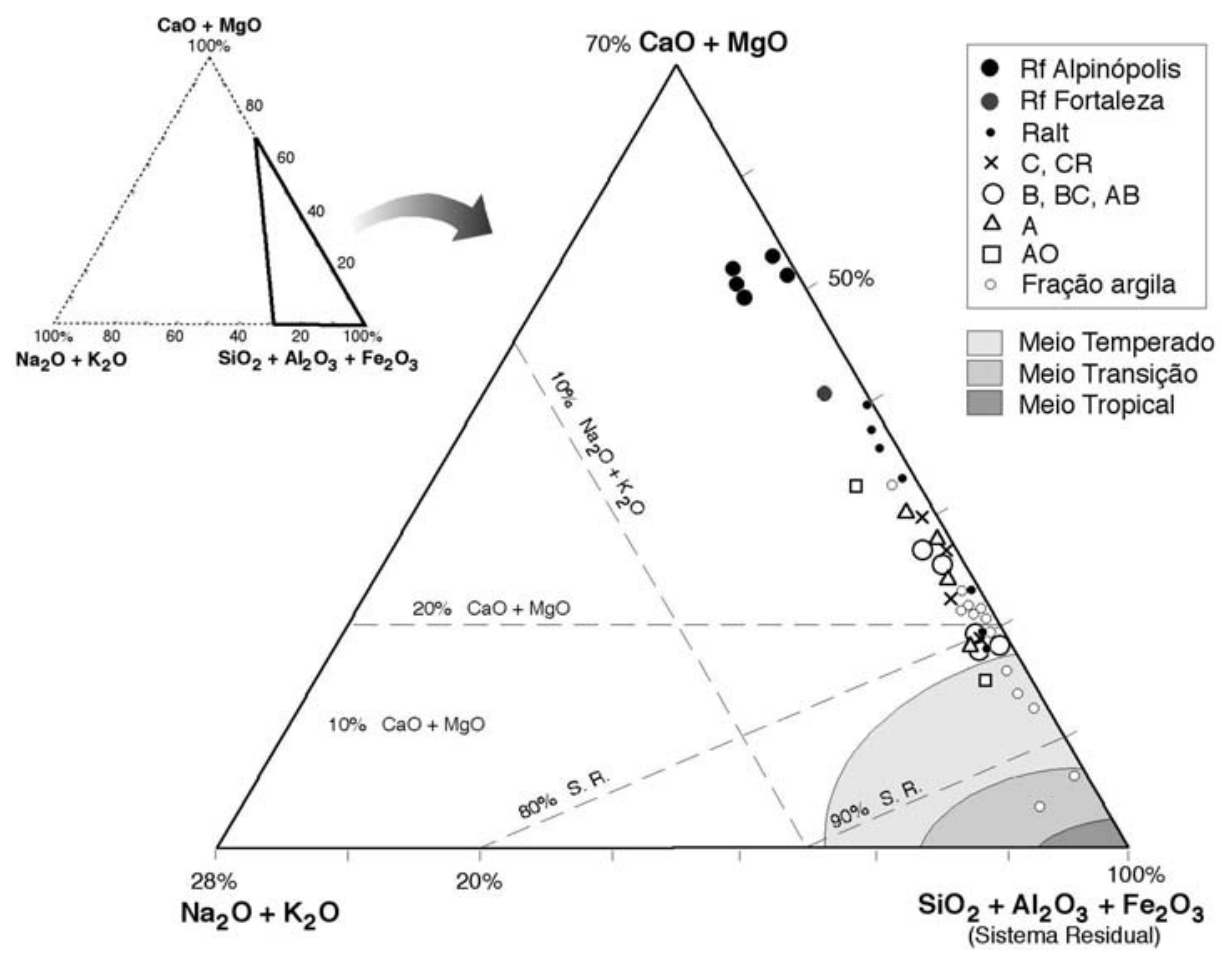

Figura 2. Avaliação da evolução geoquímica durante a alteração e pedogênese das rochas serpentinizadas, utilizando os resultados das análises químicas totais $\left(\mathrm{em} \mathrm{mol} \mathrm{kg}^{-1}\right)$ e situando-os no diagrama de Chesworth (1973). Rf: rochas frescas da região de Alpinópolis (MG) (Carvalho et al., 1993) e rocha fresca amostrada nos afloramentos associados ao perfil 1 em Fortaleza de Minas (MG); Ralt.: rochas em via de alteração.

serpentinizadas em relação à alcançada por outros materiais básicos e ultrabásicos co-genéticos em ambientes úmidos tanto subtropicais como temperados (Menegotto, 1983; Calvo de Anta et al., 1987; Vieira et al., 1991). Nesse aspecto, a fração argila, que representa a fase de evolução mais avançada, mostra perda mais intensa de elementos alcalinos e alcalinoterrosos, aparecendo ocasionalmente muito próxima ao extremo do sistema residual (argilas dos horizontes C e B de P2) (Figura 2).

Entre os constituintes majoritários do sistema residual, o Si é o elemento mais móvel (Figura 4). A dessilicificação produzida na passagem da rocha fresca para os horizontes B produz perda entre 70 e $88 \%$ do valor inicial de $\mathrm{SiO}_{2}$, em relação ao $\mathrm{Al}_{2} \mathrm{O}_{3}$, considerado como imóvel. A mobilidade geoquímica do $\mathrm{Fe}$ em relação ao $\mathrm{Al}$ parece estar relacionada com a hidrologia dos solos. No caso de P1, que ocupa o topo convexo de uma colina onde o solo é mais bem drenado, o Fe apresenta mobilidade menor ou igual ao $\mathrm{Al}$ (Figura 5). Os perfis P2 e P3 são mais rasos e a topografia local é plana, o que pode ser a causa de certo hidromorfismo temporário nos períodos chuvosos prolongados. O exame micromorfológico revelou, localmente, nítidas feições de segregação e difusão de Fe nos horizontes Bi desses dois perfis (Vidal-Torrado et al., 2006), as quais evidenciam a maior mobilidade geoquímica do Fe em relação ao $\mathrm{Al}$ (Figura 5).
Esses resultados são mais facilmente reconhecidos a partir dos balanços iso- $\mathrm{Al}_{2} \mathrm{O}_{3}$ realizados, considerando como referência (mais preservada), em todos os casos, a rocha coletada no perfil 1 de Fortaleza de Minas (RFF) (Figura 5). Nas primeiras fases da alteração da rocha o elemento que sofre perdas mais intensas é o $\mathrm{Na}$, com perda superior a $90 \%$ quando o material está ainda em estado de rocha consolidada (Ra1 e Ra2). As perdas relativas de Mg estão entre 60 e $90 \%$ nestas fases iniciais. O Ca mostra evolução similar à do Mg em P2 e P3, embora com perda inicial menos pronunciada.

A tendência aluminizante do processo é constatada mais nitidamente quando se considera a composição da fração argila, cujo conteúdo de $\mathrm{Al}_{2} \mathrm{O}_{3}$ oscila entre 43 e $164 \mathrm{~g} \mathrm{~kg}^{-1}$ (Quadro 3). As relações molares $\mathrm{SiO}_{2} /$ $\mathrm{Al}_{2} \mathrm{O}_{3}$ decrescem da rocha (46) até o saprolito (25 para 15), os horizontes do solo (15 para 5) e a fração argila (3). A variação da relação molar $\mathrm{MgO} / \mathrm{Al}_{2} \mathrm{O}_{3}$ é, para a mesma seqüência, 34,15 a 5 e 6 a 2,1 .

O K apresenta comportamento singular como conseqüência do seu escasso conteúdo nessas rochas, o que permite detectar ganho relativo nos solos devido à influência de outros materiais do entorno (granitos). Nos horizontes superficiais dos solos também parece haver influência biogênica nos elementos mais implicados nos ciclos biogeoquímicos (Figura 5). Na 
Quadro 2. Composição química de rochas com diferentes graus de alteração e dos horizontes dos solos estudados

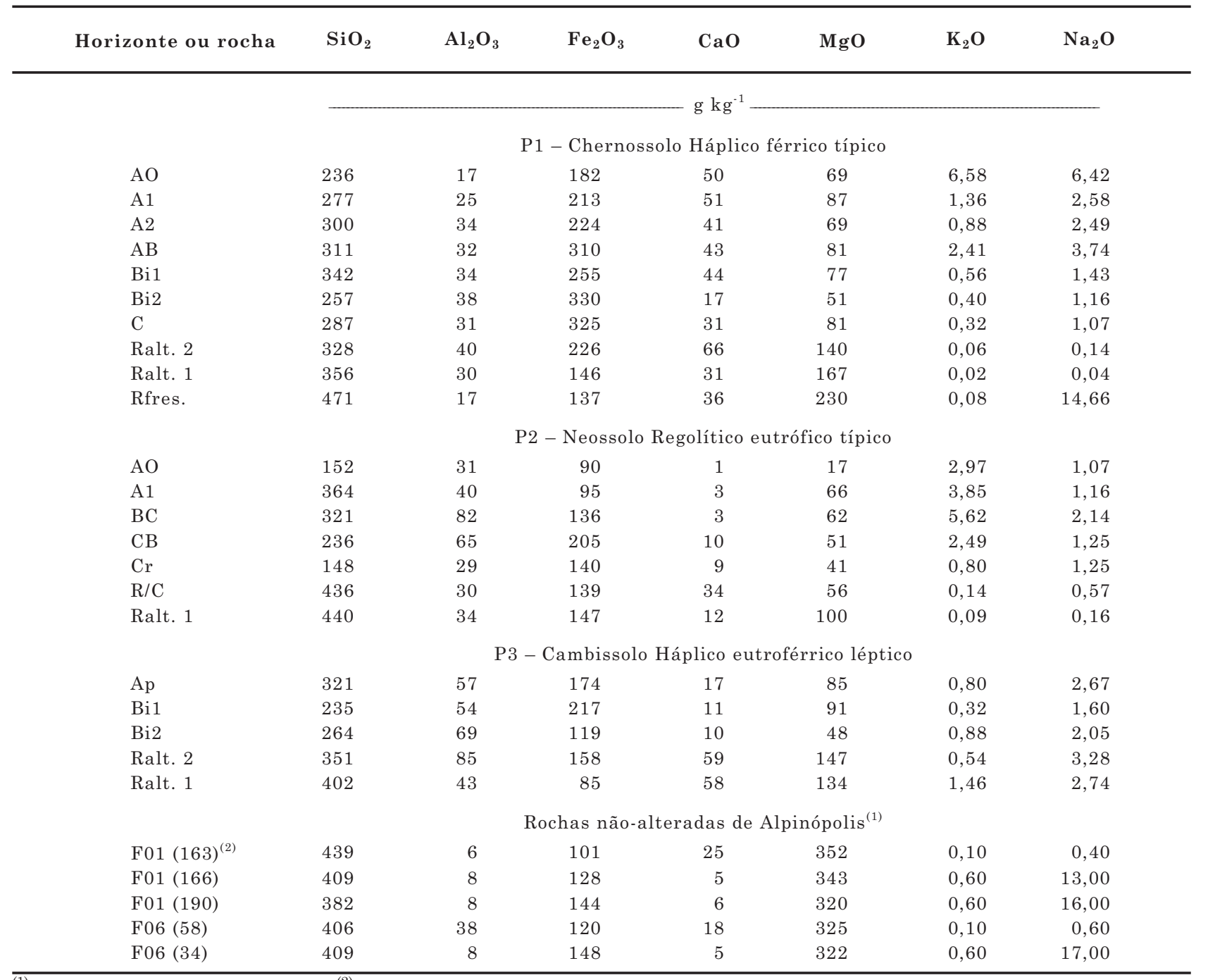

(1) Dados de Carvalho et al. (1993). ${ }^{(2)}$ Profundidade, em metros, das respectivas sondagens geológicas. Rfres.: rocha fresca; Ralt.: rocha alterada/córtex de alteração (2 menos alterada que 1$)$.

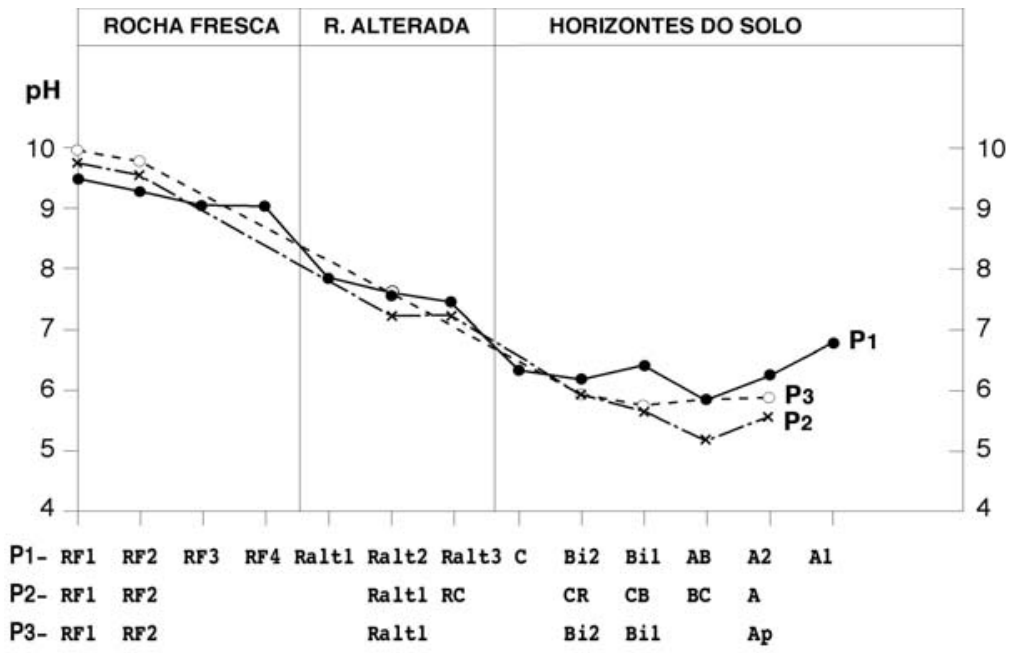

Figura 3. Evolução do pH de abrasão nos perfis de alteração estudados. 


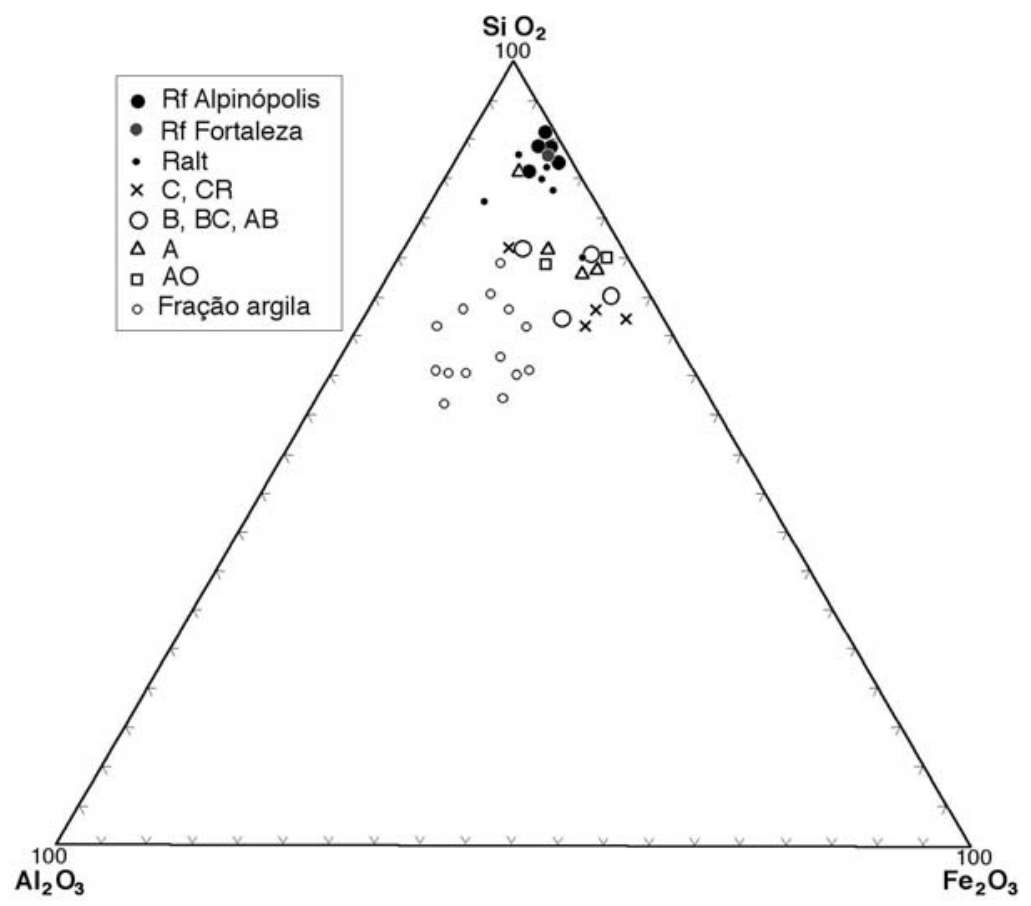

Figura 4. Variação dos componentes do Sistema Residual (Chesworth, 1973), nos diferentes estádios de alteração e ganhos (balanço iso-alumínio) dos componentes majoritários nos perfis 1.
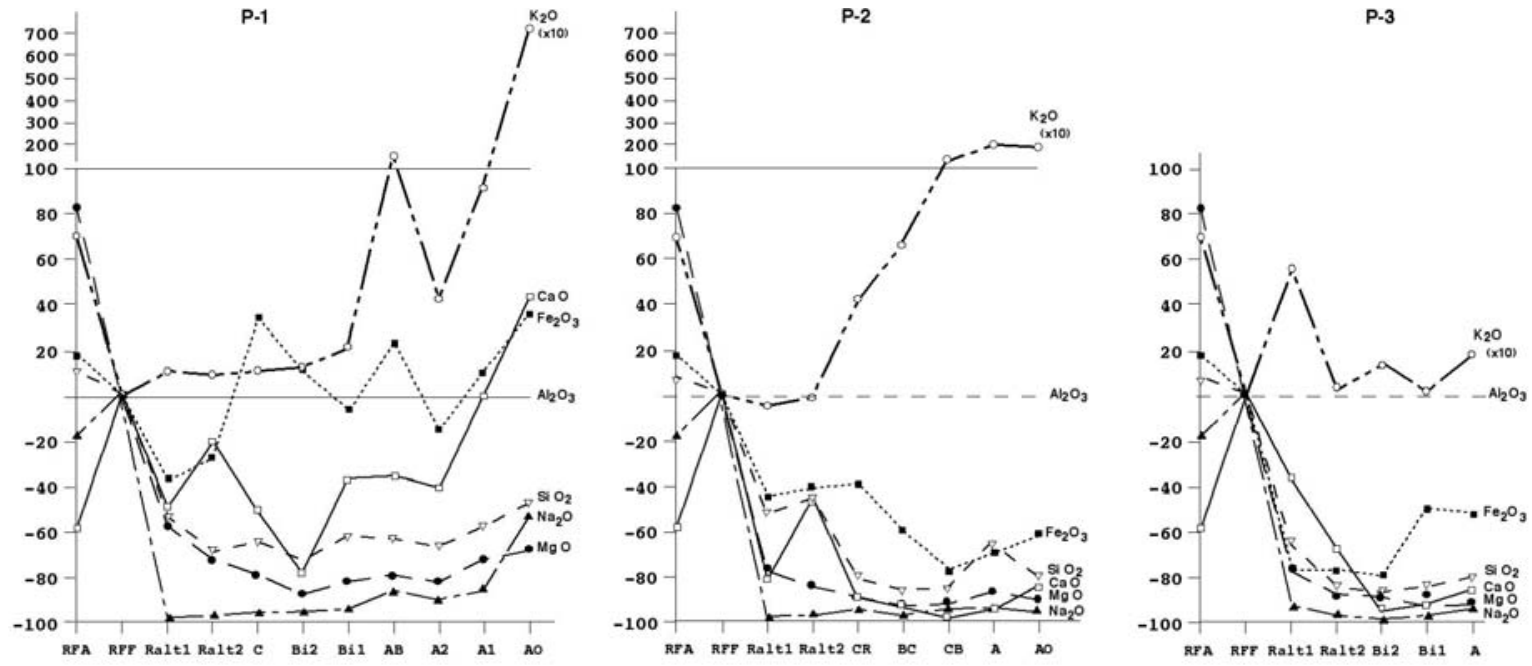

Figura 5. Perdas e ganhos (balanço isoalumínio) dos componentes majoritários nos perfis de alteração estudados. Tomou-se como referência inicial a composição da rocha fresca do perfil 1 (RFF). RFA: rocha fresca de Alpinópolis (Carvalho et al., 1993).

análise da fração argila, a relação $\mathrm{MgO} / \mathrm{Al}_{2} \mathrm{O}_{3}$ é 1,8 vez mais elevada na superfície do que no horizonte $\mathrm{C}$ de $\mathrm{P} 1$ (Quadro 3); para o $\mathrm{CaO} / \mathrm{Al}_{2} \mathrm{O}_{3}$ e $\mathrm{Na}_{2} \mathrm{O} / \mathrm{Al}_{2} \mathrm{O}_{3}$ esse fator é de 3,9 e 7,7 respectivamente. Para o $\mathrm{K}$, a relação $\mathrm{K}_{2} \mathrm{O} / \mathrm{Al}_{2} \mathrm{O}_{3}$ chega a apresentar índice de acumulação relativa de 50, o que apóia a hipótese de aporte exógeno, além da contribuição biogênica.

Em síntese, o processo de alteração é característico de um sistema subtrativo, com perda quase total de
$\mathrm{Na}$ e de $\mathrm{Ca}$ e $\mathrm{Mg}$ (em dois dos três perfis) e dessilicificação entre 60 e $80 \%$, com tendência aluminizante dos materiais residuais (aluminizante e ferruginizante em P1). A seqüência global das relações de mobilidade nos elementos majoritários é: $\mathrm{Na}>\mathrm{Mg}>\mathrm{Ca}, \mathrm{Si}>\mathrm{Fe}>\mathrm{Al}$.

Nos horizontes do solo, a relação Fe ditionito $\left(\mathrm{Fe}_{\mathrm{DC}}\right) /$ Fe total $\left(\mathrm{Fe}_{\mathrm{t}}\right)$ oscila entre 0,21 e 0,60. Em todos os perfis, a quantidade de $\mathrm{Fe}_{\mathrm{DC}}$ é maior nos horizontes $\mathrm{B}$ 
Quadro 3. Composição química da fração argila de horizontes selecionados dos solos estudados

\begin{tabular}{|c|c|c|c|c|c|c|c|}
\hline Horizonte ou rocha & $\mathrm{SiO}_{2}$ & $\mathrm{Al}_{2} \mathrm{O}_{3}$ & $\mathrm{Fe}_{2} \mathrm{O}_{3}$ & $\mathrm{CaO}$ & MgO & $\mathbf{K}_{2} \mathbf{O}$ & $\mathrm{Na}_{2} \mathrm{O}$ \\
\hline & \multicolumn{6}{|c|}{ P1 - Chernossolo Háplico férrico típico } & \\
\hline A1 & 137 & 43 & 59 & 28 & 40 & 0,7 & 1,0 \\
\hline A2 & 150 & 56 & 114 & 6 & 42 & 0,1 & 2,0 \\
\hline $\mathrm{AB}$ & 120 & 60 & 116 & 5 & 35 & 0,1 & 1,0 \\
\hline Bi1 & 156 & 85 & 146 & 11 & 38 & 0,2 & 2,0 \\
\hline Bi2 & 131 & 73 & 98 & 9 & 32 & 0,4 & 0,2 \\
\hline \multirow[t]{2}{*}{$\mathrm{C}$} & 163 & 66 & 96 & 11 & 35 & 0,2 & 0,2 \\
\hline & \multicolumn{6}{|c|}{ P2 - Neossolo Regolítico eutrófico típico } & \\
\hline $\mathrm{BC}$ & 124 & 89 & 82 & 1 & 25 & 1,6 & 0,2 \\
\hline $\mathrm{CR}$ & 186 & 164 & 136 & 1 & 16 & 1,2 & 0,2 \\
\hline \multirow[t]{2}{*}{$\mathrm{R} / \mathrm{C}$} & 193 & 154 & 96 & 1 & 7 & 0,9 & 1,0 \\
\hline & \multicolumn{6}{|c|}{ P3 - Cambissolo Háplico eutroférrico léptico } & \\
\hline Bi1 & 120 & 81 & 116 & 1 & 22 & 1,9 & 0,2 \\
\hline $\mathrm{Bi} 2$ & 137 & 106 & 76 & 1 & 22 & 0,4 & 2,0 \\
\hline
\end{tabular}

e $\mathrm{C}$ do que nos horizontes $\mathrm{A}$, o que novamente sugere o rejuvenescimento superficial dos solos (Figura 6). Nos horizontes B, entre 40 e $50 \%$ do Fe encontra-se em formas extraíveis em ditionito citrato, provavelmente como óxidos, o que indica grau de evolução similar ou ligeiramente mais avançado em comparação com solos desenvolvidos sobre serpentinitos em ambientes temperados (Bonifácio et al., 1997; Aguilar et al., 1998; Calvo de Anta et al., 1999). As baixas relações $\mathrm{Fe}_{\mathrm{OX}} / \mathrm{Fe}_{\mathrm{DC}}$ e $\mathrm{Al}_{\mathrm{OX}} / \mathrm{Al}_{\mathrm{DC}}$ (entre 0,06 a 0,24 e 0,20 a 0,50, respectivamente) indicam a escassa ocorrência de óxidos de $\mathrm{Fe}$ e de $\mathrm{Al}$ de baixo grau de ordem estrutural.

\section{Tendências da evolução mineralógica}

A composição mineralógica da fração argila é discutida em detalhe em Vidal-Torrado et al. (2006). Apresenta mescla de minerais herdados (tremolita, talco e clorita), de transformação direta (interestratificados clorita-vermiculita e cloritaesmectita) e, por último, de minerais neoformados (caulinita, goethita e hematita) (Quadro 4), podendo neoformar também esmectitas e, talvez, talco nas fases iniciais de alteração.

A probabilidade de ocorrência e a evolução das fácies minerais caracterizadas foram estimadas por meio de diversos procedimentos. Os dados da composição química da fração sólida foram aplicados ao diagrama de fases proposto por Righi \& Meunier (1995) para o sistema $\mathrm{Mg}-\mathrm{Fe}-\mathrm{Al}$, constituintes básicos das camadas de octaedros dos minerais de argila formados a partir da alteração de rochas básicas e ultrabásicas (Figura 7). Os resultados evidenciam que a composição da rocha não-alterada corresponde ao campo de estabilidade do talco, que inclui também outros minerais primários, como as cloritas trioctaédricas e a serpentina (crisotilo, antigorita). As rochas em fase de alteração e dos horizontes A, B e C do solo apresentam assembléias trifásicas do tipo saponita-vermiculita trioctaédrica-nontronita, enquanto a composição da fração argila corresponde a assembléias do tipo bifásica vermiculita trioctaédricanontronita ou trifásica vermiculita trioctaédricavermiculita dioctaédrica-nontronita, nas quais as vermiculitas seriam dominantes.

A variação dos dados da composição química durante as fases de alteração e pedogênese evidenciam tendência global de desestabilização da paragênese produzida durante a serpentinização (talco, clorita e serpentinas) e de incremento dos filossilicatos $2: 1$, com predomínio de minerais do tipo das vermiculitas tri e dioctaédricas, como é usual em meios onde, embora haja maior mobilidade relativa, o $\mathrm{Mg}$ continua dominando em relação ao Al. Assim, em termos geoquímicos, o processo de alteração pode ser caracterizado globalmente como uma bissialitização (Pedro, 1979), com maior possibilidade de ocorrência para as fases trioctaédricas. A presença de minerais 1:1 seria mais própria das fases de maior evolução pedogenética.

Uma avaliação da evolução mineral atual dos sistemas pode ser feita a partir dos dados da composição de uma solução de equilíbrio do solo. A fase fluida obtida no laboratório da mistura solo-água (1:2), após uma semana de tempo de contato, poderia ser utilizada como uma aproximação dessa solução de 
P-1
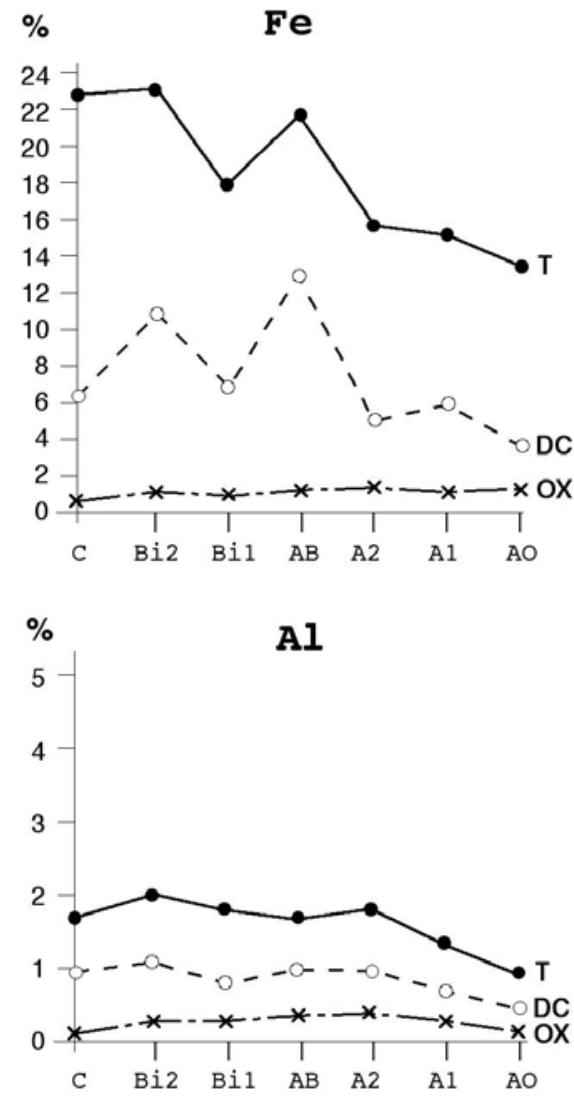

P-2

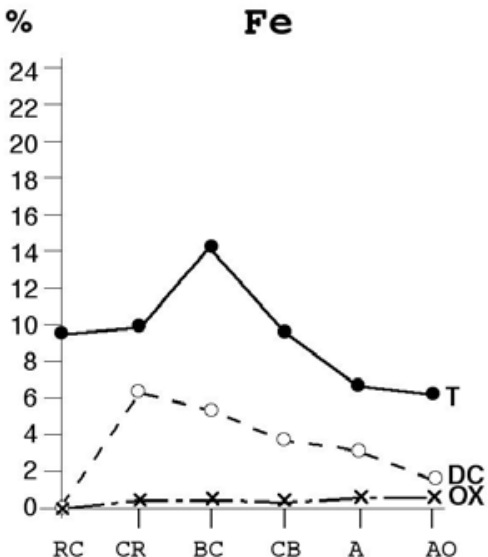

$\%$

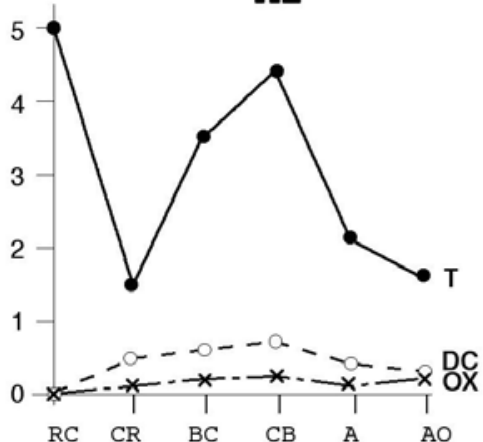

P-3
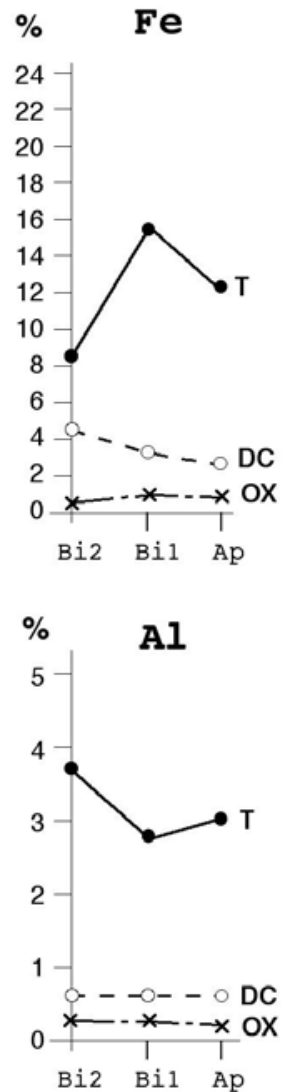

Figura 6. Análise total e extrações seletivas de Fe e Al. DC: ditionito-citrato (Buurman et al., 1996); OX: oxalato ácido de amônio (Blackmore et al., 1987).

Quadro 4. Composição mineralógica da fração argila de horizontes selecionados e da rocha de origem dos solos estudados

Horizonte

Profundidade

$\mathrm{cm}$

P1 - Chernossolo Háplico Férrico típico

$\begin{array}{lc}\mathrm{AB} & 30-50 \\ \mathrm{Bi}_{1} & 50-90 \\ \mathrm{C} & 110-130 \\ \text { Rocha } & \mathrm{Tr}, \mathrm{Cl}, \mathrm{Tc}, \mathrm{Sp}, \mathrm{Op} .\end{array}$

P2 - Neossolo Regolítico eutrófico típico

$\mathrm{Bi}$

BC

Rocha

$\mathrm{AB}$

$\mathrm{Bi}$

Rocha
$50-80$

$80-130$

$\mathrm{Sp}, \mathrm{Tr}, \mathrm{Cl}, \mathrm{Op}$.

P3 - Cambissolo Háplico eutroférrico léptico

$$
\text { 10-40 }
$$$$
\text { 40-70 }
$$

Tr, Sp, O/Sp, P, Cl, Tc.
Mineralogia da fração argila

Tc, Cl-V, Cl, K, Tr, G, H

Tc, Cl-V, Cl, K, Tr, G, H

$\mathrm{Tc}, \mathrm{Cl}-\mathrm{V}, \mathrm{Cl}-\mathrm{E}, \mathrm{K}, \mathrm{Cl}, \mathrm{Tr}, \mathrm{G}$

Tc, Cl-V, Cl-E, Cl, K, G, H

$\mathrm{Tc}, \mathrm{Cl}-\mathrm{V}, \mathrm{Cl}-\mathrm{E}, \mathrm{Cl}, \mathrm{K}, \mathrm{G}$

Tc, Cl, K, Cl-V, Tr, G, H

Tc, Cl, Cl-V, Cl-E, K, Tr , G, H

Abreviações: Sp: serpentina; Cl: clorita; Tr: tremolita; Tc: talco; K: caulinita; Cl-V: interestratificado clorita-vermiculita; Cl-E: interestratificado clorita-esmectita; G: goethita; H: hematita. O/Sp: olivina serpentinizada; P: piroxênio; Op: opacos. A mineralogia das rochas foi observada em microscópio petrográfico (Vidal-Torrado et al., 2006). 


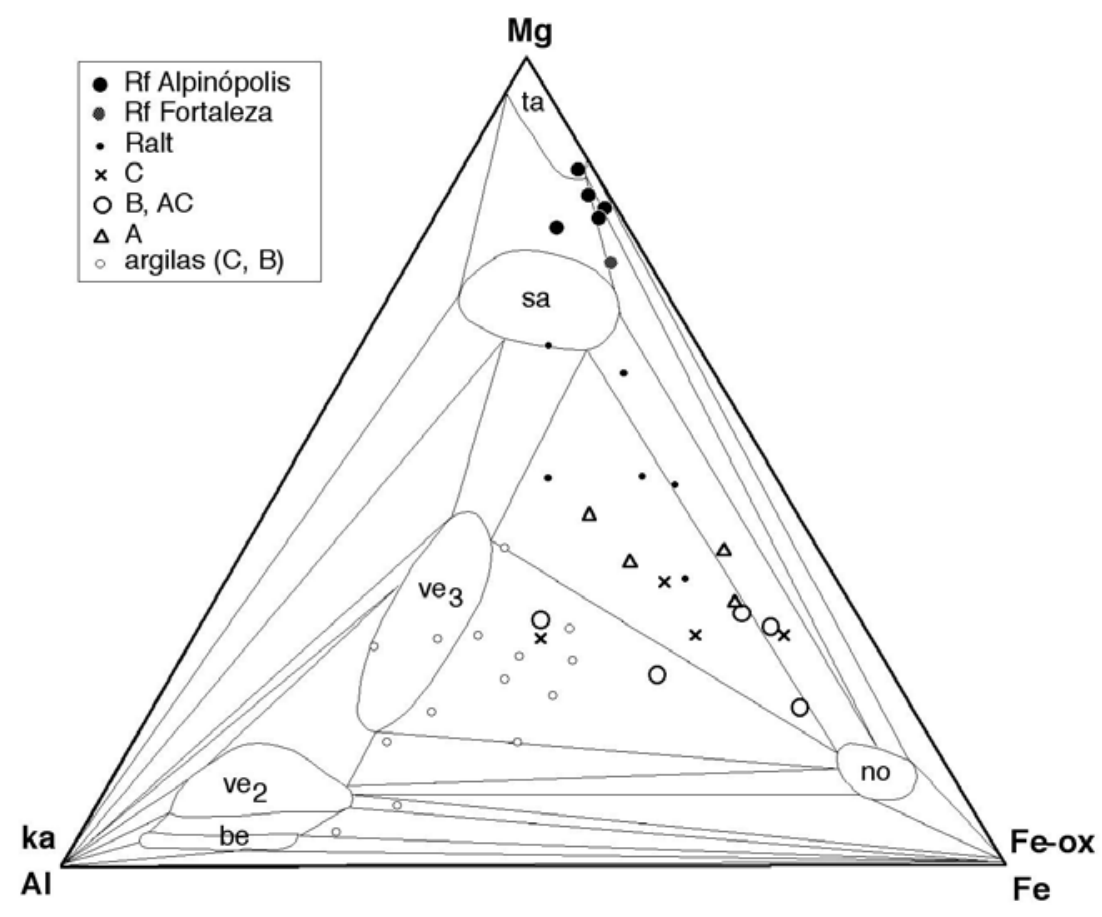

Figura 7. Avaliação da possibilidade de ocorrência das fases minerais a partir da composição química da fase sólida, aplicando-se o diagrama de fases de Righi \& Meunier (1995) para o sistema Fe-Al-Mg. Símbolos como na figura 2; ka: caulinita e Fe-ox: óxidos de ferro; ta: talco; sa: saponita; ve3: vermiculita trioctaédrica; ve2: vermiculita dioctaédrica; be: beidellita; no: nontronita.

equilíbrio (Calvo de Anta et al., 1999). Os resultados obtidos nessas soluções (Quadro 5) apresentam valores de $\mathrm{pH}$ entre 6,1 e 7,4, com concentrações de $\mathrm{Mg}^{2+} \mathrm{e}$ $\mathrm{Ca}^{2+}$ entre 0,3 e $3,5 \mathrm{mg} \mathrm{L}^{-1}$, com predomínio entre os ânions do $\mathrm{HCO}_{3}^{-}\left(2\right.$ a $\left.35 \mathrm{mg} \mathrm{L}^{-1}\right)$ e quantidades bem menores de $\mathrm{Cl}^{-}, \mathrm{SO}_{4}{ }^{=}$e $\mathrm{NO}_{3}^{-}$. Como síntese, a condutividade elétrica das soluções e, portanto, a força iônica resultaram ser baixas, oscilando esta última entre $10^{-4}$ e $6,10^{-4}$.

O Si oscila entre 2,97 e 8,03 $\mathrm{mg} \mathrm{L}^{-1}$, valores que, em geral, são mais elevados que a composição de equilíbrio com quartzo e que podem ser explicados pela possível presença de silício amorfo, relativamente freqüente em formações dessa natureza.

Considerando as constantes de equilíbrio termodinâmico para diferentes minerais, utilizadas pelo programa de Kharaka et al. (1989), foram calculados os índices de saturação mineral (Quadro 6). Os resultados seguem as tendências deduzidas a partir da análise da composição química, dos dados mineralógicos obtidos por DRX e das observações microscópicas, evidenciando menor saturação (instabilidade ou metaestabilidade) para os minerais primários, como clorita, crisotilo (serpentina), talco, olivina e, inclusive, para uma esmectita trioctaédrica rica em $\mathrm{Mg}$ (saponita), em relação à maior estabilidade termodinâmica dos filossilicatos 2:1 dioctaédricos ricos em Fe (nontronitas, por exemplo) e, ou, das caulinitas. Há ainda supersaturação para alguns tipos de esmectita e, também, para gibbsita, que apresenta, no entanto, os índices mais baixos. Entre os óxidos de Fe ocorre maior supersaturação para hematita do que para goethita.

Apesar disso, há também saturação e, portanto, metaestabilidade de minerais primários, como o talco e as serpentinas, o que, junto com a presença da caulinita, esmectita e minerais vermiculíticos, confirma que a evolução mineralógica produzida durante a alteração e pedogênese não alcançou um estádio de equilíbrio termodinâmico, o qual seria próprio da formação de solos ferralíticos, e sim que se trata de uma fase inicial ou incipiente, em que coexistem minerais facilmente intemperizáveis com minerais metaestáveis e os termodinamicamente estáveis.

Uma nova aproximação pode ser obtida a partir de diagramas de equilíbrio do sistema $\mathrm{SiO}_{2}-\mathrm{Al}_{2} \mathrm{O}_{3}-\mathrm{H}_{2} \mathrm{O}$, considerando reações de dissolução/precipitação de diferentes minerais (Figura 8a). Os resultados conduzem a conclusões similares às obtidas anteriormente. Nas condições de umectação ensaiadas, verificou-se supersaturação para espécies 2:1 trioctaédricas (E). No entanto, a maior estabilidade termodinâmica corresponde a uma caulinita bem cristalizada (K1). De toda forma, uma vez que a cristalização desses minerais é um processo de formação muito lento (Sposito, 1981), optou-se pela utilização de diagramas com constantes de equilíbrio de caulinitas de baixo grau de ordem estrutural (K2), 
Quadro 5. Composição dos estratos de equilíbrio solo/água (relação 1:2) de horizontes subsuperficiais dos perfis 1,2 e 3

\begin{tabular}{|c|c|c|c|c|c|c|c|c|c|c|c|c|c|c|c|c|}
\hline Hor. & pH & $\mathbf{C E}$ & $\mathrm{NO}^{2-}$ & $\mathrm{NO}^{3-}$ & $\mathrm{SO}_{4}{ }^{2-}$ & $\mathrm{Cl}^{-}$ & $\mathrm{HCO}_{3}^{-}$ & $\mathbf{F}^{-}$ & $\mathrm{Ca}^{2+}$ & $\mathrm{Mg}^{2+}$ & $\mathrm{Na}^{+}$ & $\mathbf{K}^{+}$ & $\mathrm{NH}_{4}^{+}$ & $\mathbf{F e}$ & Al & $\mathrm{Si}$ \\
\hline & & $\mu \mathrm{S} \mathrm{cm} \mathrm{cm}^{-1}$ & & & & & & 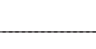 & $-\mathrm{mg} \mathrm{I}$ & & & & & & & - \\
\hline & & & \multicolumn{14}{|c|}{ P1 - Chernossolo Háplico férrico típico } \\
\hline Bi1 & 7,36 & 79,8 & $<0,05$ & 0,79 & 1,14 & 4,92 & 35,38 & 0,05 & 3,49 & 3,20 & 0,71 & 0,95 & 1,60 & 1,10 & 0,10 & 6,05 \\
\hline $\mathrm{Bi} 2$ & 6,98 & 45,3 & 0,63 & 2,24 & 0,61 & 1,82 & 11,69 & 0,02 & 1,85 & 1,77 & 0,84 & 0,58 & 0,90 & 3,63 & 0,25 & 8,03 \\
\hline $\mathrm{C}$ & 6,84 & 31,1 & $<0,05$ & 2,19 & 0,21 & 3,91 & 9,35 & $<0,02$ & 1,20 & 1,38 & 0,50 & 0,36 & 0,59 & 0,77 & 0,09 & 6,82 \\
\hline \multicolumn{17}{|c|}{ P2 - Neossolo Regolítico eutrófico típico } \\
\hline $\mathrm{BC}$ & 6,13 & 27,0 & 0,12 & 1,32 & 0,35 & 2,38 & 2,34 & $<0,02$ & 0,65 & 1,04 & 0,50 & 1,04 & 0,50 & $<0,10$ & $<0,05$ & 3,19 \\
\hline $\mathrm{CR}$ & 6,10 & 18,6 & $<0,05$ & 0,62 & 1,77 & 2,06 & 7,17 & $<0,02$ & 0,34 & 0,53 & 0,44 & 0,76 & 0,44 & 0,21 & $<0,05$ & 4,40 \\
\hline \multicolumn{17}{|c|}{ P3 - Cambissolo Háplico eutroférrico léptico } \\
\hline Bi1 & 6,76 & 30,6 & 0,12 & 1,66 & 0,19 & 1,00 & 9,64 & $<0,02$ & 0,57 & 0,57 & 0,55 & 0,85 & 1,57 & 1,54 & 0,13 & 4,40 \\
\hline $\mathrm{Bi} 2$ & 6,53 & 13,2 & $<0,05$ & 1,04 & 0,13 & 0,77 & 3,14 & $<0,02$ & 0,28 & 0,28 & 0,49 & 0,29 & 0,53 & 0,33 & $<0,05$ & 2,97 \\
\hline
\end{tabular}

Quadro 6. pH, força iônica (I), atividades de $\mathrm{Ca}, \mathrm{Mg}$, $\mathrm{Si}$ e $\mathrm{Al}$ ( $\mathrm{Al}^{3+}$ e outras espécies iônicas) e estabilidade mineral de acordo com os índices de saturação nos extratos de materiais de horizontes subsuperficiais dos perfis 1, 2 e 3, em condições naturais (a) e simulando uma evaporação de 75 \% da umidade (b). Os minerais são apresentados em ordem decrescente de seu índice de saturação

\begin{tabular}{|c|c|c|c|c|c|c|c|c|c|}
\hline Hor. & $\mathrm{pH}$ & $\mathbf{I}$ & $\mathrm{Ca}^{2+}$ & $\mathrm{Mg}^{2+}$ & $\mathrm{H}_{4} \mathrm{SiO}_{4}$ & $\mathrm{Al}^{3+}$ & Alx & Minerais estáveis & Minerais metaestáveis \\
\hline (a) & \multicolumn{9}{|c|}{ P1- Chernossolo Háplico Férrico típico } \\
\hline Bi1 & 7,36 & $6,10^{-4}$ & $7,810^{-5}$ & $1,210^{-4}$ & $2,610^{-4}$ & $2,010^{-12}$ & $\mathrm{Al}(\mathrm{OH})_{4}^{-} 3,510^{-6}$ & no $>$ he $>$ k $>$ sm $>$ go $>$ gb $>$ ca & $\mathrm{cl}, \mathrm{cr}, \mathrm{en}, \mathrm{o}, \mathrm{sa}, \mathrm{se}, \mathrm{ta}$ \\
\hline $\mathrm{Bi} 2$ & 6,98 & $4,10^{-4}$ & $4,210^{-5}$ & $6,710^{-5}$ & $3,510^{-4}$ & $1,410^{-10}$ & $0,810^{-6}$ & no $>$ he $>$ go $>$ k $>$ sm $>$ gb $>$ ca & $\mathrm{cl}, \mathrm{cr}, \mathrm{en}, \mathrm{o}, \mathrm{sa}, \mathrm{se}, \mathrm{ta}$ \\
\hline $\mathrm{C}$ & 6,84 & $3,10^{-4}$ & $2,810^{-5}$ & $5,310^{-5}$ & $3,010^{-4}$ & $1,610^{-10}$ & $2,310^{-6}$ & no $>$ he $>$ k $>$ sm $>$ gb $>$ ca & cl,cr,en,o,sa,se,ta \\
\hline \multicolumn{10}{|c|}{ P2 - Neossolo Regolítico eutrófico típico } \\
\hline $\mathrm{BC}$ & 6,13 & $2,10^{-4}$ & $1,510^{-5}$ & $4,010^{-5}$ & $1,410^{-4}$ & $1,410^{-9}$ & $\mathrm{Al}(\mathrm{OH})^{2+} 3,010^{-7}$ & no $>$ he $>$ k $>$ sm $>$ gb $>$ go & cl,cr,en,o,sa, se,ta,ca \\
\hline $\mathrm{CR}$ & 6,10 & $2,10^{-4}$ & $8,010^{-6}$ & $2,010^{-5}$ & $2,010^{-4}$ & $1,610^{-9}$ & $3,010^{-7}$ & no $>$ he $>$ k $>$ sm $>$ gb $>$ go $>$ ca & cl,cr,en,o,sa,se,ta \\
\hline \multicolumn{10}{|c|}{ P3 - Cambissolo Háplico eutroférrico léptico } \\
\hline Bi1 & 6,76 & $2,10^{-4}$ & $1,310^{-5}$ & $2,210^{-5}$ & $2,010^{-4}$ & $4,010^{-10}$ & $3,010^{-6}$ & no $>$ he $>$ k $>$ sm $>$ gb $>$ go $>$ ca & $\mathrm{cl}, \mathrm{cr}, \mathrm{en}, \mathrm{o}, \mathrm{sa}, \mathrm{se}, \mathrm{ta}$ \\
\hline $\mathrm{Bi} 2$ & 6,53 & $1,10^{-4}$ & $6,710^{-6}$ & $1,110^{-5}$ & $1,310^{-4}$ & $1,610^{-10}$ & $2,010^{-7}$ & no $>$ he $>$ k $>$ sm $>$ gb $>$ go & cl,cr,en,o,sa,se,ta,ca \\
\hline (b) & \multicolumn{9}{|c|}{ P1 - Chernossolo Háplico Férrico típico } \\
\hline Bi1 & 7,54 & & $2,810^{-4}$ & $4,310^{-4}$ & $1,010^{-3}$ & $1,510^{-5}$ & $\mathrm{Al}(\mathrm{OH})_{4} \quad 1,410^{-5}$ & $\mathrm{sm}>\mathrm{k}>\mathrm{gb}>\mathrm{ca}>\mathrm{cl}>\mathrm{sa}>\mathrm{ta}$ & \\
\hline $\mathrm{Bi} 2$ & 9,35 & & $1,510^{-4}$ & $2,410^{-4}$ & $9,810^{-4}$ & $0,210^{-18}$ & $3,510^{-5}$ & $\mathrm{sa}>\mathrm{se}>\mathrm{sm}>\mathrm{k}>\mathrm{ca}>\mathrm{gb}>\mathrm{cl}>\mathrm{en}>\mathrm{cr}>\mathrm{ta}$ & \\
\hline $\mathrm{C}$ & 8,60 & & $1,010^{-4}$ & $1,910^{-4}$ & $1,010^{-3}$ & $7,810^{-17}$ & $1,210^{-5}$ & $\mathrm{sa}>\mathrm{cl}>\mathrm{sm}>\mathrm{k}>\mathrm{ta}>\mathrm{cr}>\mathrm{O}>\mathrm{ca}$ & \\
\hline \multicolumn{10}{|c|}{ P2 - Neossolo Regolítico eutrófico típico } \\
\hline $\mathrm{BC}$ & 5,57 & & $5,710^{-5}$ & $1,510^{-4}$ & $6,010^{-4}$ & $3,610^{-8}$ & $\mathrm{Al}(\mathrm{OH})^{2+} \quad 6,010^{-7}$ & $\mathrm{k}>\mathrm{sm}>\mathrm{ca}$ & \\
\hline $\mathrm{CR}$ & 5,84 & & $3,010^{-5}$ & $8,010^{-5}$ & $8,010^{-4}$ & $1,510^{-8}$ & & $\mathrm{k}>\mathrm{sm}>\mathrm{ca}$ & \\
\hline \multicolumn{10}{|c|}{ P3 - Cambissolo Háplico eutroférrico léptico } \\
\hline Bi1 & 7,51 & & $5,010^{-5}$ & $8,010^{-5}$ & $8,010^{-5}$ & $2,610^{-12}$ & & $\mathrm{sm}>\mathrm{k}>\mathrm{ca}$ & \\
\hline Bi2 & 6,82 & & $2,610^{-5}$ & $4,210^{-5}$ & $5,110^{-4}$ & $7,910^{-11}$ & & $\mathrm{sm}>\mathrm{k}>\mathrm{ca}$ & \\
\hline
\end{tabular}

Abreviações: cl: clorita; no: nontronita; he: hematita; go: goethita: sa: saponita; ta: talco; k: caulinita; gb: gibbsita; sm: esmectita; ca: calcedônia; cr: crisotilo; o: olivina; se: sepiolita. 
que seriam os minerais 1:1 que se formariam inicialmente (Macías et al., 1992). Aplicando esse conceito cinético proposto por Sposito (1981), a evolução mineralógica desses sistemas passaria por uma neoformação inicial de esmectitas mais estáveis nos sistemas fissurais iniciais com alto $\mathrm{pH}$, com progressiva evolução em direção às caulinitas de baixo grau de ordem estrutural (K2) e, finalmente, uma caulinita bem cristalizada (K1).
Considerando o diagrama do sistema $\mathrm{SiO}_{2}-\mathrm{Al}_{2} \mathrm{O}_{3}$ $\mathrm{MgO}-\mathrm{H}_{2} \mathrm{O}$, elaborado por Chesworth (1997) a partir dos dados de Bowers et al. (1984) (Figura 8b,c), podese notar a tendência de degradação do talco, das cloritas e de outros minerais primários dos sistemas estudados, em direção ao campo de estabilidade da caulinita. A aplicação dos dados obtidos por simulação de processos de evaporação aos diagramas de equilíbrio da figura 8 conduz a resultados similares.

(a)

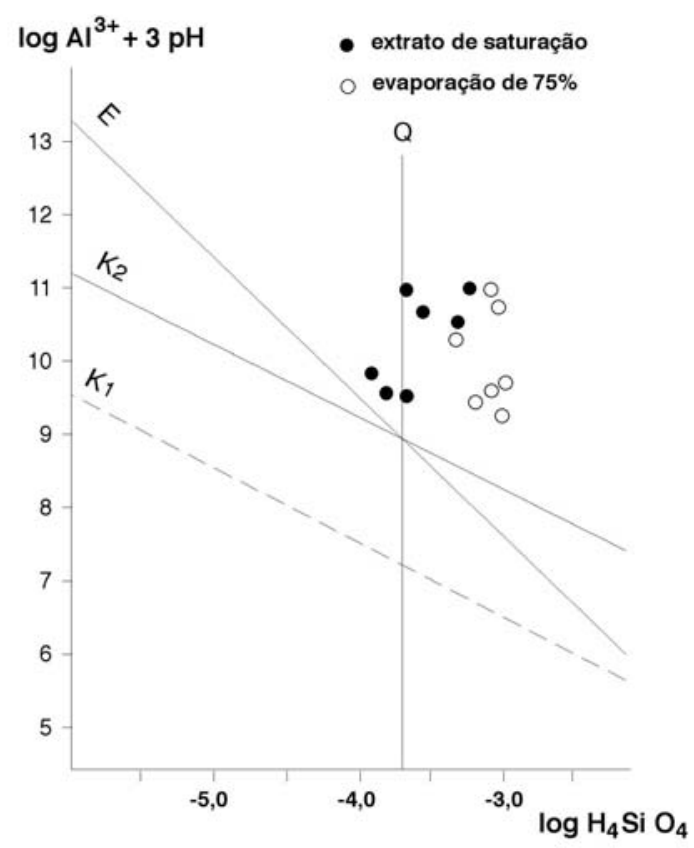

(b)

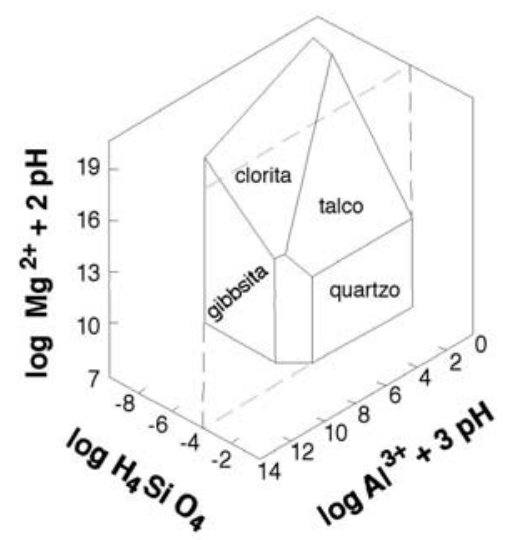

(c)

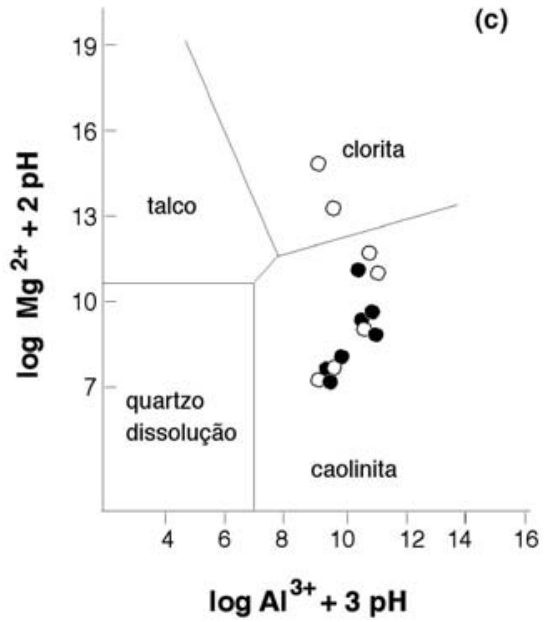

Figura 8. Avaliação da estabilidade dos minerais a partir dos extratos de saturação dos horizontes B e C dos solos derivados de serpentinitos em condições de equilíbrio e após um processo de evaporação de 75 \% de umidade (simulação por computador). (a) Diagrama do sistema $\mathrm{SiO}_{2}{ }^{-} \mathrm{Al}_{2} \mathrm{O}_{3}{ }^{-} \mathrm{H}_{2} \mathrm{O}$, utilizando as constantes termodinâmicas de duas caulinitas de diferentes graus de cristalinidade (caulinita k1: Sarazin, 1979; caulinita k2: Kittrick, 1966) e uma esmectita (E), considerando para esta última $\left(\mathrm{Mg}^{2+}\right)=10-3,5 \mathrm{pH}$ e $\left(\mathrm{Fe}^{2+}\right)=2,70-3 \mathrm{pH}$. (b) Aplicação do diagrama de Bowers et al. (1984), para sistema $\mathrm{SiO}_{2}-\mathrm{Al}_{2} \mathrm{O}_{3}-\mathrm{MgO}_{-}$ $\mathrm{H}_{2} \mathrm{O}$ (Chesworth, 1997 - comunicação pessoal). (c) Seção do diagrama anterior correspondente a log $\left(\mathrm{H}_{4} \mathrm{SiO}_{4}\right)=-4$. 


\section{CONCLUSÕES}

1. Em superfícies geomórficas jovens no sudoeste de Minas Gerais com clima tropical úmido e estação seca definida, a evolução morfológica (espessura e diferenciação de horizontes), química e mineralógica dos solos derivados de rochas serpentinizadas é moderada em comparação à existente sobre outros tipos de rochas básicas e ultrabásicas no mesmo ambiente, apresentando similaridades com a evolução observada em ambientes úmidos subtropical e temperado sobre superfícies e litologia semelhantes. Caracteriza-se por uma importante perda de $\mathrm{Na}$ e $\mathrm{Mg}$ e, em menor proporção, de Ca e Si. O Al é o elemento menos móvel do sistema, junto com o Fe, quando os solos são bem drenados, e o K tem importante contribuição exógena.

2. Nas condições atuais, os minerais primários, freqüentes na fração argila, são termodinamicamente instáveis. O sistema se encontra muito próximo do campo de equilíbrio dos filossilicatos 2:1 trioctaédricos, o que é confirmado pela presença comum de cloritavermiculita e clorita-esmectita na fração argila, evoluindo para espécies dioctaédricas.

3. Caulinita bem cristalizada seria o mineral neoformado mais estável termodinamicamente em todos os solos, mas há de se considerar que aspectos cinéticos podem favorecer a persistência tanto de espécies 2:1 trioctaédricas metaestáveis como de caulinitas de baixo grau de cristalinidade.

4. O processo de alteração pode ser definido como uma bissialitização, que pode coincidir localmente com ferruginização, formação de minerais trioctaédricos secundários por transformação direta de estrutura e, talvez, também por neoformação, coexistindo com minerais primários residuais. As fases mais evoluídas tendem à monossialitização, mas estão ainda distantes de alcançar as condições características da ferralitização.

\section{AGRADECIMENTOS}

Os autores agradecem ao Sr. Elias Luis Calvo, pela confecção das figuras e gráficos. À Mineração Serra da Fortaleza e ao Sr. José de Souza Alves, pela permissão e pelo apoio para trabalhar em suas áreas.

\section{LITERATURA CITADA}

ADAMSON, D.A.; SELKIRK, J.M. \& SEPPELT, R.D. Serpentine, harzburgite and vegetation on subantartic Macquarie Island. Artic Alpine Res., 25:216-219, 1993.

AGUILAR, J.; CALVO DE ANTA, R.; FERNÁNDEZ ONDOÑO, E. \& MACIAS, F. Geoquímica de la alteración y edafogénesis de rocas serpentinizadas de la Sierra Bermeja (Málaga). Edafología, 5:135-151, 1998.
ALEXANDER, E.B.; WILDMAN, W.E. \& LYNN, W.C. Ultramafic (serpentinic) mineralogy class. In: KITTRICK, J.A., ed. Mineral classification of soils. Madison, Soil Science society of America, 1985. p.135-146. (Special Publication, 16)

AMERICAN SOCIETY FOR TESTING AND MATERIALS ASTM. Standard test method for major and minor elements in coal and coke ash by atomic absorption. Method D 3682-87. In: STORER R.A., ed. Annual Book of ASTM Standards, gaseous fuels, Coal and Coke. Version 5.05. Philadelphia, 1991. p.369-374.

BERTSCH, P.M. \& BLOOM, P.R. Aluminum. In: SPARKS, D.L., ed. Methods of soil analysis. Chemical methods, Part 3. Madison, Soil Science Society of America, 1996. p.517-550. (SSSA Book Series, 5)

BLAKEMORE, L.C.; SEARLE, P.I. \& DALY, B.K. Methods for chemical analysis of soils. Lower Hutt, New Zealand Soil Bureau, Department of Scientific and Industrial Research, 1987. 103p.

BONIFÁCIO, E.; ZANINI, E.; BOERO, V. \& FRANCHINIANGELA, M. Pedogenesis in a soil catena on serpentinite in north-western Italy. Geoderma, 75:33-51, 1997.

BOWERS, T.; JACKSON, K. \& HELGESON, H. Equilibrium activity diagrams. Berlin, Springer-Verlag, 1984. 397p.

BULMER, C.E.; LAVKUBICH, L.M. \& SCHREIER, H.E. Morphology, chemistry and mineralogy of soils derived from serpentinite and tephra in southwestern British Columbia. Soil Sci., 154:72-82, 1992.

BUURMAN, P.; van LAGEN, B. \& VELTHORST, E.J. Manual for soil and water analysis. Leiden, Backhuys Publishers, 1996. $314 \mathrm{p}$.

CALVO DE ANTA, R.; MACÍAS, F. \& BUURMAN, P. Procesos de alteración y neoformación mineral en medios serpentínicos de Galicia. Cuad. Lab. Xeol. Laxe, 11:161$170,1987$.

CALVO DE ANTA, R.; VIDAL-TORRADO, P.; FERNANDEZ, E.; MACIAS, F.; GONZALEZ, C. \& TOUZA, R. Weathering and pedogenesis on serpentinized rocks under mediterranean, humid temperate and humid tropical climates. In: INTERNATIONAL MEETING ON SOILS WITH MEDITERRANEAN TYPE OF CLIMATE, 6., Barcelona, 1999. Proceedings. 1999. p.392-394.

CAMARGO, O.A.; MONIZ, A.C.; JORGE, J.A. \& VALADARES, J.M.A.S. Métodos de análise química, mineralógica e física de solos do Instituto Agronômico de Campinas. Campinas, Instituto Agronômico, 1986. 94p (Boletim Técnico, 106)

CARVALHO, S.G.; SOARES, P.C.; ANTONIO, M.C.; ZANARDO, A. \& OLIVEIRA, M.A.F. Geologia da seqüência vulcano-sedimentar de Alpinópolis (MG). R. Bras. Geoc., 23:38-51, 1993.

CHESWORTH, W. Aplicação do diagrama de Bowers et al. (1984) para o sistema $\mathrm{SiO}_{2}-\mathrm{Al}_{2} \mathrm{O}_{3}-\mathrm{MgO}-\mathrm{H}_{2} \mathrm{O}$. Santiago de Compostela, 1997. (Comunicação pessoal)

CHESWORTH, W. The parent rock in the genesis of soils. Geoderma, 10:215-225, 1973.

CLEAVES, E.T. Chemical weathering in a humid temperate environment. Sci. Geol., 71:47-56, 1983. 
COLEMAN, R.G. \& JOVE, C. Geological origin of serpentines. In: BAKER, A.J.M.; PROCTOR, J. \& REEVES, R.D., eds. The vegetation of Ultramafic (Serpentine) Soils. INTERNATIONAL CONFERENCE ON SERPENTINE ECOLOGY, 1., Davis, 1991. Proceedings. Hampshire, Intercept, 1992. p.1-17.

EMPRESA BRASILEIRA DE PESQUISA AGROPECUÁRIA . EMBRAPA. Centro Nacional de Pesquisa de Solos. Sistema brasileiro de classificação de solos. Brasília, Embrapa Produção de Informação, 1999. 412p.

ESSON, J. Geochemistry of a nickeliferous laterite profile, Liberdade, Brazil. In: WILSON, R.C.L., ed. Residual deposits: Surface related weathering processes and materials. Oxford, Geology Society of London, 1983. p.91-99.

GRANT, W.H. Abrasion $\mathrm{pH}$ an index of chemical weathering. J. Geol., 49:392-401, 1969.

JENNY, H. The soil resource. Origin and behaviour. New York, Springer-Verlag, 1980. 377p.

KHARAKA, Y.; GUNTER, W.; AGGARWAL, P.; PERKINS, E. \& DEBRAAL, J. Solmineq.88: A computer program for geochemical modelling of water-rock interactions. Menlo Park, Geological Survey, 1989. 419p.

KITTRICK, J.A. Free energy of transformation of kaolinite from solubility measurements. Am. Mineral., 51:14571466, 1966.

LEE, B.D.; SEARS, S.K.; GRAHAM, R.C.; AMRHEIN, C. \& VALI, H. Secondary mineral genesis from chlorite and serpentine in an ultramafic soil toposequence. Soil Sci. Soc. Am. J. 67:1309-1317, 2003.

MACIAS, F.; ALVAREZ, E. \& CALVO DE ANTA, R. Minerales secundarios de sistemas edáficos y control de la concentración de aluminio en sistemas fluviales de Galicia. Cuad. Lab. Xeol. Laxe, 17:57-71, 1992.

MALPAS, J. Serpentine and the geology of serpentinized rocks. In: ROBERTS, B.A. \& PROCTOR, J., eds. The ecology of areas with serpentinized rocks. A world view. Dordrecht, Kluwer Academic, 1991. p.7-30.

MELFI, A.J.; TRESCASES, J.J. \& OLIVEIRA, S.M.B. Les "laterites" nickeliferes du Brésil. Cah. Orstom, Sér. Geol., $11: 15-42,1980$

MENEGOTTO, E. Intemperização de rochas ultrabásicas no Rio Grande do Sul, Brasil. R. Bras. Geoc., 13:178-189, 1983.

OLIVEIRA, S.M.B. \& TRESCASES J.J. Geoquímica da alteração supérgena das rochas ultramáficas de Santa Fé (Goiás, Brasil). R. Bras. Geoc., 10:244-257, 1980.

PEDRO, G. General characterization of the hydrolitic processes of weathering. Basis of the geochemical and thermodinamical methods, Sci. Sol, 93:105, 1979.

PINTO, L.F.S. \& KÄMPF, N. Solos derivados de rochas ultrabásicas no ambiente subtropical do Rio Grande do Sul. R. Bras. Ci. Solo, 20:447-458, 1996.
RABENHORST, M.C.; FOSS, J.E. \& FANNING, D.S. Genesis of Maryland soils formed from Serpentinite. Soil Sci. Soc Am. J., 46:607-616, 1982.

RAIJ, B. van; QUAGGIO, J.A.; CANTARELLA, H.; FERREIRA, M.E.; LOPES, A.S. \& BATAGLIA, O.A. Análise química do solo para fins de fertilidade. Campinas, Fundação Cargill, 1987. 165p.

RIGHI, D. \& MEUNIER, A. Origins of clays by rock weathering and soil formation. In: VELDE, B., ed. Origin and mineralogy of clays. Clays and the environment. New York, Springer Verlag, 1995. p.43-161.

ROBERTS, B.A. \& PROCTOR, J. The ecology of areas with serpentinized rocks. A world view. Dordrecht, Kluwer Academic, 1991. p.7-30.

SARAZIN, G. Géochimie de l'aluminium au cours de l'altération des granites et des basaltes sous climat témpéré. Paris, Université de Paris, 1979. 170p. (Tese de Doutorado)

SCHWERTMANN, U. \& LATHAM, M. Properties of iron oxides in some New Caledonian oxisols. Geoderma, 39:105-123, 1986.

SÉGALEN, P.; BOSCH, D.; CARDENAS, A.; CAMACHO, E.; BOULEAU, A.; GUENIN, H. \& RAMBAUD, D. Aspects mineralogiques et pédogénetiques de deux sols dérivés de péridotites dans l'ouest de Cuba. Cah. ORSTOM, sér. Pédol., 18:273-284, 1980.

SOIL SURVEY STAFF. Keys to soil taxonomy. 7.ed. Blacksburg, Pocahontas Press, 1996. 544p.

SPOSITO, G. The thermodynamics of soil solutions. Oxford, Science Publication Oxford, 1981. 223p.

TRESCASES, J.J. L'évolution géochimique supergène des roches ultrabasiques en zone tropicale. Formation des gîsements nickelifères de Nouvelle-Caledonie. Mem. ORSTOM, 78. 1975. 259p.

TRESCASES, J.J. \& OLIVEIRA, S.M.B. Alteração dos serpentinitos de Morro do Níquel (MG). In: CONGRESSO BRASILEIRO DE GEOLOGIA, 30, Recife, 1978. Anais. Recife, Sociedade Brasileira de Geologia, 1980. p.16551669 .

VIDAL-TORRADO, P. Pedogênese e geoquímica de metais pesados em solos derivados de rochas básicas e ultrabásicas na região do greenstone "Morro do Ferro" no sudoeste de Minas Gerais. Relatório científico do projeto FAPESP XX/97. 1999b Não Publicado.

VIDAL-TORRADO, P.; MACIAS, F.; CALVO, R.; CARVALHO, S. \& SILVA, A.C. Gênese de solos derivados de rochas ultramáficas serpentinizadas no sudoeste de Minas Gerais. R. Bras. Ci. Solo, 30:523-541, 2006.

VIEIRA, J.; SEQUEIRA, E.M. \& SOARES DA SILVA, M. Meteorização de serpentinitos do Nordeste de Portugal: Evolução mineralógica e qeoquímica. Coimbra, Universidade de Coimbra, 1991.p.185-199 (Memórias e Notícias, Publ. Mus. Lab. Mineral. Geol., 112) 